\title{
Trace element content of ginger and sage medicinal plants from Algeria
}

\author{
Zohra Lamari*, Rachid Larbi, Benaouda Yagoubi
}

COMENA/Research Nuclear Center of Draria, NUR Reactor Division, Draria, Algeria; ${ }^{*}$ Corresponding Author: zohralamari@yahoo.fr

Received 14 January 2010; revised 5 February 2010; accepted 10 March 2010.

\begin{abstract}
Instrumental Neutron Activation Analysis has been used to make a multi-elemental determination in the Zingiber officinalis and Salvia officinalis, plants used in traditional medicine therapy in Algeria and in most countries. The concentrations of five elements $\mathrm{Co}, \mathrm{Cr}, \mathrm{Sc}, \mathrm{Sb}$ and $\mathbf{R b}$ have been determined by long irradiation time with 2.7E13 $\mathrm{n} \cdot \mathrm{cm}^{-2} \cdot \mathrm{s}^{-1}$ thermal flux using a NUR Algerian Reactor. All these elements are present at trace levels. Their implications in Human health are herein discussed. The quality control of the measurements have been evaluated by analysing a HAY (V-10) IAEA-Standard reference material.
\end{abstract}

Keywords: Medicinal Plants; Trace Element; Biological Effects; INAA

\section{INTRODUCTION}

Sage and ginger are folk medicinal plants administered in many ways in several countries for their virtues. Partly as food additives as well as treatments for a lot of diseases. In the forms of infusion, in liquid or dry extracts, sage has been used to treat inflammations of mucous membranes such as pharyngitis caused by a viral infection [1]. In association with other plants it has been used to cure lesions caused by labial herpes [2]. One (01) g per day sage in the form of extract would be advantageous for the illness known as Alzheimers. It has also been used for calming the agitation of patients [3]. Some authors reported that the administering of dried sage sheets made it possible to improve memory, good humour and reduce anxiety [4] in patients, as well. Sage as a dry aqueous extract in the proportion of $440 \mathrm{mg}$ per day or an infusion of $4.5 \mathrm{~g}$ per day also has had an anti sudorific action [5]. Another study reportedly concerning 30 women showed that an extract containing sage and alfalfa relieved the hot flashes of menopause [6].
Observations in the laboratory has shown the antibacterial and antiviral properties of sage $[7,8]$. We attributed these anti inflammatory and neuroprotectrice effects to its rosmarinic acid content [5,9]. Other of its organic compounds such as cafeic acid, confer an antioxidant action. Ginger was one of the first Eastern spices to be consumed in Europe. Its rhizome is rich in minerals but its low concentration of sodium will adapt it perfectly to a regime without salt. It will aid in digestion and will act against motion sickness, transport pain as well as nausea and the vomiting related to pregnancy. In addition, the antioxidants which it contains would intervene in the prevention of the cardiovascular diseases and certain cancers. This plant can be consumed fresh, in powder form or crystallized in sugar.

The objective of this work is to evaluate the mineral composition of these plants which would be a great advantage in human health. Although the classification of the elements is rather difficult, some authors classify the elements as: essential; probably essential; and toxic [10-14]. The elements known as essential are: $\mathrm{Co}, \mathrm{Cr}$, Sc and $\mathrm{Rb}$ which play a big role in the constitution and maintenance of good health. However, these elements can be toxic to the body when large amounts are taken [15]. Because of this potential danger, administered doses are recommended by several international organizations such as FAO, WHO and the United States National Research Council $[10,16]$.

\section{EXPERIMENTAL}

\subsection{Medicinal Plants Collection}

Sage was collected from the Algerian national botanical garden (Jardin d'Essai El-Hamma) in Algiers. Ginger was purchased in the fresh form of rhizome from a local herbalist. Each plant was washed in de-mineralized water, then the sheets of sage and the roots of the ginger were dried using an IR lamp for one week. The dried samples were then ground into fine powder in an automatic agate mortar. 


\subsection{Elemental Determination by INAA}

The powdered samples of ginger roots and sheets of sage were individually packed in polyethylene pastilles of twelve $12 \mathrm{~mm}$ diameters. These samples were treated in association with certified standards (IAEA-SL-1, IAEA-SOIL-7). Respectively, a lake sediment and a soil, then irradiated in a NUR research reactor. For the INAA analysis process, one irradiation sheme was carried out a long irradiation time. Between 100 to $200 \mathrm{mg}$ of samples were weighed, put in aluminum capsules and irradiated in the thermal column of NUR Reactor. Together with standard reference materials, for six (06) hours with $2.7 \mathrm{E} 13 \mathrm{n} \cdot \mathrm{cm}^{-2} \cdot \mathrm{s}^{-1}$ thermal flux and $2.13 \mathrm{E} 12 \mathrm{n} \cdot \mathrm{cm}^{-2} \cdot \mathrm{s}^{-1}$ epithermal flux. After decaying for fifteen (15) days these samples were removed to appropriate containers and counted for ten (10) hours and four (04) hours, respectively for the samples and standards using a high rate spectroscopy system.

A HpGe detector having a 10\% relative efficiency and a FWHM of $2.0 \mathrm{KeV}$ for the ${ }^{60} \mathrm{Co} 1332.5 \mathrm{keV}$ gamma ray line were used for the counting system. The measurements for both samples and standards were repeated after two weeks. The accuracy of the measurements has been evaluated by analizing the biological reference material AIEA-V-10 (Hay).

\section{RESULTS AND DISCUSSION}

Table 1 shows the average concentration of five elements analized in the dried rhizome of ginger and dried sheets of sage. These concentrations were reported with standard deviations. Figure 1 shows the typical gamma spectrum obtained for Zingiber officinalis and Salvia officinalis.

The quality control of the measurement was established from the results of analizing AIEA-V-10 (Hay) standard reference material and as shown in Table 2.
For most of the elements the best agreement between the measured values and the certified values was obtained. Except for the cobalt, the certified value is a double of the measured value. The elements found in the dried plants were: $\mathrm{Co}, \mathrm{Cr}, \mathrm{Sb}, \mathrm{Sc}$ and Rb. All were present at trace levels. The Co and Cr are essential components for men and animals. The importance of cobalt is that the components vitamin B12 and chromium are known to be involved in glucose metabolism. It is a beneficial nutrient but it can be Carcinogenic. That depends on its amount and its chemical form [18]. A Federal

Table 1. Average elemental concentrations and standard deviations ( $\mu \mathrm{g} / \mathrm{g}$ ) of the Zingiber officinalis and Salvia officinalis.

\begin{tabular}{ccc}
\hline Element & Zingiber Officinale & Salvia Officinalis \\
\hline Co & $0.480 \pm 0.045$ & $0.845 \pm 0.081$ \\
$\mathrm{Cr}$ & $0.57 \pm 0.12$ & $1.67 \pm 0.35$ \\
$\mathrm{Sc}$ & $0.099 \pm 0.012$ & $0.520 \pm 0.065$ \\
$\mathrm{Sb}$ & $0.0240 \pm 0.0025$ & $0.107 \pm 0.013$ \\
$\mathrm{Rb}$ & $3.12 \pm 0.27$ & $6.430 \pm 0.567$ \\
\hline
\end{tabular}

Table 2. Average elemental concentrations and standard deviations $(\mu \mathrm{g} / \mathrm{g})$ of the IAEA-certified material V10 (HAY).

\begin{tabular}{ccc}
\hline \multirow{2}{*}{ Element } & \multicolumn{2}{c}{ V10 (Hay Powder) } \\
\cline { 2 - 3 } & Measured value & Reported value [17] \\
\hline Co & $0.067 \pm 0.007$ & $0.13 \pm 0.015$ \\
Cr & $4.06 \pm 1.15$ & $6.5 \pm 0.75$ \\
Sc & $0.012 \pm 0.002$ & $0.014 \pm 1.5 \mathrm{E}-4$ \\
Rb & $8.48 \pm 0.82$ & $7.6 \pm 0.25$ \\
Sb & & $*$ \\
\hline
\end{tabular}

"No reported value.

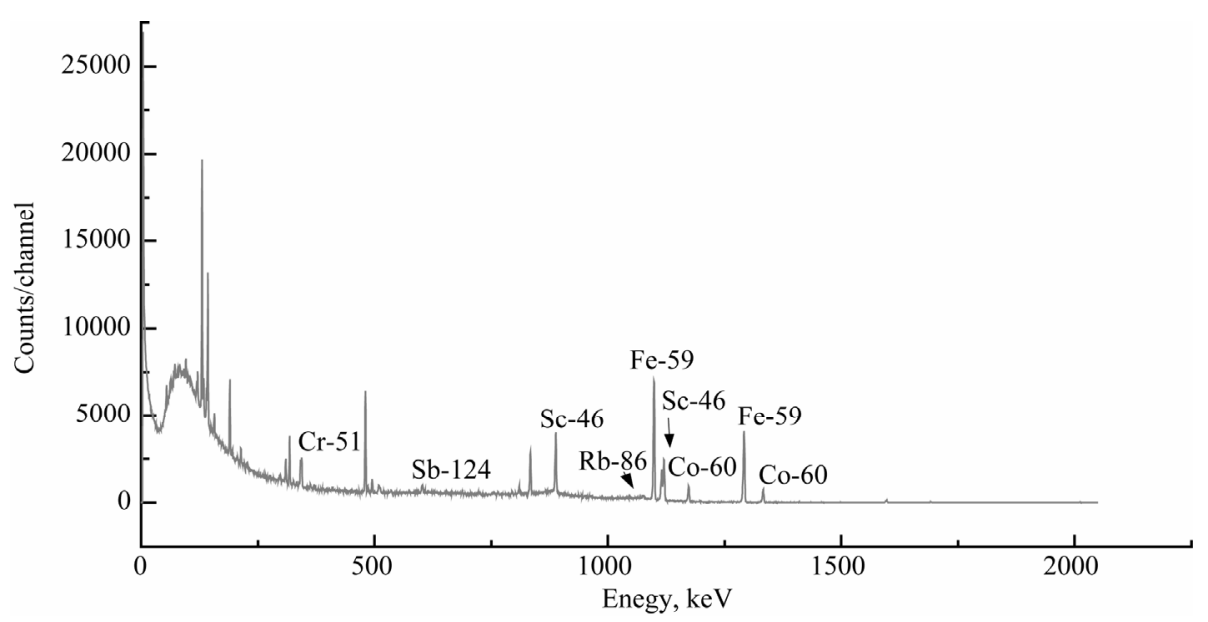

Figure 1. Typical long-lived spectrum induced by thermal neutrons for the Zingiber officinalis. 
agency in the USA has prepared the toxicological profile [19].

Although there are no reported physiological effects of $\mathrm{Rb}$; its accumulation in the body system could be detrimental to health [20]. The Sc is a rare element which in small quantities tends to accumulate in the liver when it is absorbed. The antimony is naturally found in the environment and is used in medicine therapy for parasitic infections, but persons who have taken too much of these medicines will have health problems which will make them more conscious of the dangers of this element.

\section{CONCLUSIONS}

The INAA represents a good technique for analysis of biological samples and determining trace elements. The potentiel curative action of these herbs is linked to their organic and mineral composition. Sage and ginger have been used many times in Algeria in traditional medicine therapy. They can be an excellent natural source of mineral trace elements intervening in physiological regulations, but they should be administered with precaution to avoid the bioaccumulation of these same elements whose presence can be dangerous in maintaining good health.

\section{REFERENCES}

[1] Hubbert, M., Sievers, H., et al. (2006) Efficacy and tolerability of a spray with Salvia officinalis in the treatment of acute pharyngitis-A randomized, double-blind, placebo-controlled study with adaptive design and interim analysis. European Journal of Medical Research, 31, 20-26.

[2] Saller, R. and Buechi, S. (2001) Combined herbal preparation foe topical treatement of herpes labialis. Forsch Komplementarmed Klass Naturheilkd, 8, 373-382.

[3] Akhondzadeh, S. and Noroozian, M. (2003) Salvia officinalis extract in the treatement of patients with mild to moderate Alzheimer's disease: A double blind, randomized and placebo-controlled trial. Journal of Clinical Pharmacy and Therapeutic, 28, 53-59.

[4] Kennedy, D. and Pace, S. (2006) Effects of cholinesterase inhibitingsage (Salvia officinalis) on mood, anxiety and performance on a psychological stressor battery. Neuropsychopharmacology, 31, 845-852.

[5] ESCOP Monographs on the Medicinal (1996) Uses of PLANTS drugs-salvia folium. Centre for Complementary Health Studies, Université d'Exter, Grande-Bretagne.

[6] De Leo V. and Lanzetta, D. (1998) Treatementof neurovegetative menopausal symptoms with a phytotherapeutic agent. Minerva Ginecologica, 50, 207-211.
[7] Osawa, K. and Matsumoto, T. (1991) The inhibitory effect of plant extracts on the collagenolytic activity and cytotoxicity of human gingival fibroplsts by Porphyromonas gingivalis crude enzyme. The Bulletin of Tokyo Dental College, 32, 1-7.

[8] Chiba, K. and Takakuwa, T. (1992) Inhibitory effect of acylphologlucinol deruvatives on the replication of veicular stomatitis virus. Bioscience, Biotechnology, and Biochemistry, 56, 1769-1772.

[9] Luvone, T. and De Fillips, D. (2006) The spice sage and its active ingredient rosmarinic acid protect PC12cells from amyloid-betapeptide-induced neurotoxicity. Journal of Pharmacology and Experimental Therapeutics, 317, 1143-1149.

[10] Joint FAO/WHO expert consultation on Human Vitamin and Mineral Rrequierments. Bangkok, September 1998.

[11] Machara, A.V. (2001) Determination of mineral constituents in duplicate portion diets of two university students groups by Instrumental Neutron Activation Analysis. Journal of Radioanalytical and Nuclear Chemistry, 249, pp. 21-24. doi:10.1023/A:1013267825653

[12] Parr, R.M. (1987) Application of nuclear analytical techniques in human nutrition research as exemplified by research programmes of the IAEA. Journal of Radioanalytical and nuclear chemistry, 110, pp 491-502. doi:10.1007/BF02035539

[13] Pennington, J.A.T and Young, B. (1990) Iron, copper, zinc, manganese, selenium and iodine in foods from the United States total diet study. Journal of Food Composition and Analysis, 3, pp. 166-184. doi:10.1016/0889-1575(90)90022-E

[14] Pham, M., et al. (1997) Determination of rare earth elements in rice by INAA and ICP-MS. Journal of Radioanalytical and Nuclear Chemistry, 217, pp. 95-99. doi:10.1007/BF02055355

[15] National Academy of Sciences (2003) Dietary reference intake. National Academy Press, Washington DC. http://books.na.edu/books0309072794/html/1.html]7/24/ $\underline{03}$

[16] Expert Committee (1996) Trace elements in human nutrition and health. FAO/IAEA/WHO, WHO, Geneva.

[17] Analytical Quality Control Services (1994-1995) 31.

[18] Salem, H. and Kates, S.A. (1989) Speciation, bioavailability, and systemic distribution of chromium from Whetlerite dust. Science of The Total Environment, 86, 59-64. doi:10.1016/0048-9697(89)90193-9

[19] Anonymous (1988) Toxicological profile for chromium. ATSDR TP-88/10, ATSDR, USPHS, ORNL, TN.

[20] Dim, L.A., Funtua, I.I., Oyewale, A.O., Grass, F., Umar, I.M., Gwozdz, R. and Gwardo, U.S., (2004) Determination of some elements in Ageratum conyziode: A tropical medicinal plant, using neutron activation analysis. Journal of Radioanalytical and Nuclear Chemistry, 261, 225228. 